\title{
TOEIC SCORE PREDICTION ACCORDING TO STUDENT'S LEARNING PERFORMANCE ON UNIVERSITY ENGLISH COURSES
}

\author{
Yi-Jie Ju, \& Cheng-Hsuan Li \\ Graduate Institute of Education Information and Measurement, \\ National Taichung University of Education (Taiwan)
}

\begin{abstract}
With the development of globalization, "English" has become an important international language. The test of English for international communication (TOEIC) was established in 1947 by the Educational Testing Service (ETS). The test is designed for non-native English people. The TOEIC score represents the familiarity of the subjects in communicating with others in English in the international workplace. The TOEIC is based on the English language of daily life in the workplace, so it is often used as the industry's standard for measuring the English communication of job applicants.

The study object is students of the Department of Applied English from the University of Technology, Taiwan. The department uses the students' TOEIC of simulation score as an assessment tool to check the student's learning effectiveness in the four years of college. The purpose is to ensure that the student's workplace English communication ability meets the needs of the industry and strengthen the student's employment ability.

For understanding students' TOEIC performance in advance, the learning performances of required English courses (at least three courses) in Grade 2, 3, and 4 were collected and applied to predict their TOEIC scores. The traditional linear model, linear regression (LR), and an advanced nonlinear machine learning model, support vector regression (SVR), were used and compared in this study. Comparing the true TOEIC scores and the prediction TOEIC scores, the average absolute differences of LR are between 21 and 63. The average absolute differences of the nonlinear models, SVR, are between 14-34, whose range is quite small. Hence the prediction of SVR is more accurate than the traditional and linear model, LR. The prediction results can help teachers to understand students' abilities. Teachers can provide some personalized teaching materials according to the predicted achieved results of students to increase students learning performance on TOEIC.
\end{abstract}

Keywords: TOEIC, learning performance prediction, machine learning, artificial intelligence.

\section{Introduction}

In order to connect with the world, "English" has become an important international language. In 2019, the Taiwan government proposed the "Blueprint for the Development Taiwan into a Bilingual National by 2030". The policy aims to build Taiwan into a bilingual country by 2030 and enhance the competitiveness of Taiwanese nationals to enhancing their English proficiency (National Development Council, 2019), which shows the importance of English to Taiwan.

Moreover, companies gradually pay attention to English communication skills in the workplace, and English communication has become an important skill in the workplace due to the connection with the world. There are many ways to identify English ability in Taiwan, such as TOEIC, GEPT, Cambridge Assessment English, TOEFL, CSEPT and other tests. The test methods and expressions of different tests are different according to their goals. TOEIC scores are for identification When a job seeker (or employee) is familiar with English in an international workplace environment, the industry often uses it as a standard to measure the job seeker's English communication level.

The participants of this research test are students from the Department of Applied English at a university of technology in Taiwan. The department uses TOEIC as a tool to check students 'learning effectiveness and has a graduation threshold. Students must have a TOEIC of 750 points (CEFR B2: high class) before graduation, that ensures students' workplace English communication ability meets the needs of the industry, and strengthen students' employability in the workplace. In terms of learning effectiveness check, after the students are enrolled, the department will conduct a TOEIC simulation test on each semester. We hope students can gradually achieve TOEIC 750 points or more in English course training. 
Hence, this study wants to understand whether students' scores of TOEIC can be predicted by the scores of courses in the university. Moreover, the department can help students whose predicted scores are below a certain criterion.

\section{Literature review}

\subsection{TOEIC}

The test of English for international communication (TOEIC) was established in 1947 by the Educational Testing Service (ETS). The test is designed for non-native English people. The TOEIC score represents the familiarity of the subjects in communicating with others in English in the international workplace, it is often used as the industry's standard for measuring the English communication of job applicants.

TOEIC $®$ is divided into TOEIC $®$ Listening and Reading Tests and TOEIC $®$ Speaking and Writing Tests. In the listening part, you will listen to various questions and short conversations recorded in English, and answer multiple-choice questions based on what you hear. The reading section requires reading various topics and answering multiple-choice questions based on incomplete sentences, incorrect recognition or text completion, and reading paragraphs (Donald E. Powers et al., 2013). The oral test is to present and express the content of six types of test questions and give a review score after digital recording. The writing test is to pass three types of test questions and must organize words or articles that fit the situation. In this study, we use the student's listening and reading simulation scores to analyze data.

\subsection{Linear regression (LR)}

Regression analysis uses the linear relationship between two variables for interpretation and prediction. LR is to analyze the linear relationship between the independent variable (X) and the dependent variable (Y) (Qiu, Hao-Zheng, 2013) when the linear relationship hypothesis holds, and the linear variable is called simple linear regression (SLR), more than one independent variable is called multiple linear regression (MLR). The purpose is to find a function that can best represent all the observed data, and point out the relationship between the variable and the phase we want to understand. In addition to explaining the past data, we can also predict the future value of the dependent variable from the independent variable. The function equation is: $y=\beta 0+\beta 1 \mathrm{x}+\varepsilon(\beta 0$ : intercept, $\beta 1$ : slope, $\varepsilon$ : error $)$ (Lu, Hui-Fen, 2017). This study uses multiple linear regression for prediction.

\subsection{Support vector regression (SVR)}

Nonlinear regression is widely used in various fields and is an extension of linear regression. When the dependent variable (y) and the independent variable (x) cannot be presented in the form of a linear function, and the various curves of different types appear on the graph, the analysis is performed by nonlinear regression. The solution of nonlinear regression is divided into linearization and non-linearization. The linearizable regression model refers to the process of transforming it into a linear regression model independently, such as Multiplication Model and Reciprocal Model; the nonlinear regression model can be converted to a certain function to make it becomes a linear function. Therefore, it is necessary to use the nonlinear model to calculate the change of the estimated value (T.H. Lin, S.S. Lai, 2007). The more common non-linear regression prediction models such as the quadratic curve equation, exponential curve equation, and Logistic curve equation produce multiple models (Lu, Hui-Fen, 2017).

SVR is derived from Support Vector Machine (SVM), which is one of the nonlinear regression models, the purpose is to find out the most hyperplane in space to accurately predict the distribution of data (Lu, Hui-Fen, 2017) Is a learning algorithm based on the principle of structural risk minimization (Kong, Fan-Yu, et al., 2007). SVR can be divided into linear support vector regression (LVR) and nonlinear support vector regression (NLVR). It uses training data to establish regression equations that the testing data or the minimum error prediction result. The regression equation is $f(x)=(w x)+b, w \in R$, $\mathrm{b} \in \mathrm{R}$ (w: weight vector, b: constant) (Lu, Si-Xian, 2015, Lu, Hui-Fen, 2017).

\section{Methods and results}

In this study, multiple linear regression (MLR) and support vector regression (SVR) were used for analysis. This study collects the final performance of required subjects (at least three courses) and the TOEIC simulation test courses with every semester for students in the second to fourth grades. This study uses the $\mathrm{R}$ program to predict and analyze the listening, reading and total scores of the TOEIC. The required subjects courses of the department are progressive teaching, which mainly cultivates students' five basic skills of listening, speaking, reading, writing, and translating in English, so as to gradually improve the passing rate of graduation threshold for students with TOEIC. The course map is shown in Figure 1. 
Figure 1. Required Course Map.

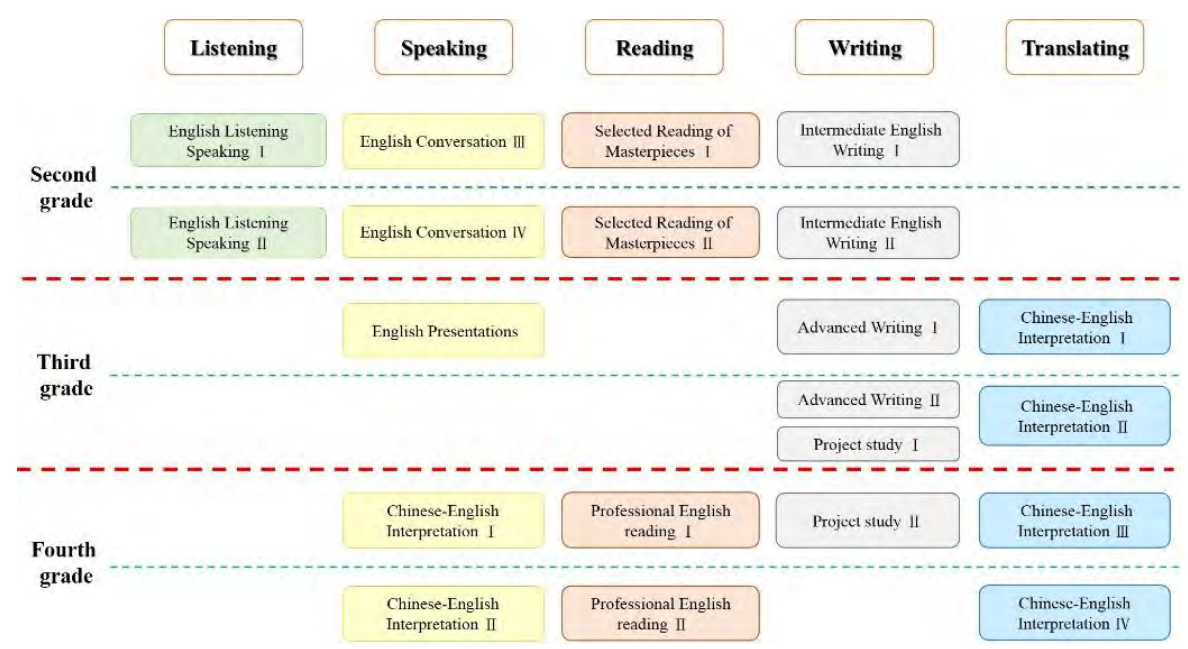

Table 1. RMSE of LR and SVR.

\begin{tabular}{cccc|cc|c}
\multicolumn{2}{c}{ Grade } & \multicolumn{2}{c}{ Second grade } & \multicolumn{2}{c}{ Third grade } & Fourth grade \\
\hline \multicolumn{2}{c}{ Semester } & Autumn & Spring & Autumn & Spring & Autumn \\
\hline \multirow{3}{*}{ LR } & Listening & 42.7710 & 55.8744 & 36.9909 & 79.0964 & 41.7422 \\
\cline { 2 - 7 } & Reading & 40.1051 & 39.3890 & 47.8523 & 63.8081 & 25.1763 \\
\cline { 2 - 7 } & Total & 62.0870 & 80.5034 & 70.7357 & 133.0488 & 45.4825 \\
\hline \multirow{3}{*}{ SVR } & Listening & 31.3008 & 37.1885 & 28.8447 & 23.5114 & 41.3727 \\
\cline { 2 - 7 } & Reading & 33.3493 & 30.2924 & 39.2760 & 33.5456 & 22.0953 \\
\cline { 2 - 7 } & Total & 41.2312 & 54.9448 & 55.0252 & 38.0821 & 40.0228 \\
\hline
\end{tabular}

Table 2. MAE of LR and SVR.

\begin{tabular}{cccc|cc|c}
\multicolumn{2}{c}{ Grade } & \multicolumn{2}{c}{ Second grade } & \multicolumn{2}{c}{ Third grade } & Fourth grade \\
\hline \multicolumn{2}{c}{ Semester } & Autumn & Spring & Autumn & Spring & Autumn \\
\hline \multirow{3}{*}{ LR } & Listening & 28.1674 & 43.1615 & 28.8514 & 28.1674 & 33.2461 \\
\cline { 2 - 7 } & Reading & 29.6696 & 31.5038 & 40.7336 & 29.6696 & 21.6283 \\
\cline { 2 - 7 } & Total & 45.8481 & 63.8348 & 54.2891 & 45.8481 & 38.3814 \\
\hline \multirow{3}{*}{ SVR } & Listening & 16.6184 & 24.1239 & 20.6457 & 16.6184 & 19.0205 \\
\cline { 2 - 7 } & Reading & 20.5391 & 18.2430 & 25.7040 & 20.5391 & 14.3539 \\
\cline { 2 - 7 } & Total & 27.5920 & 34.8158 & 33.3631 & 27.5920 & 20.6807 \\
\hline
\end{tabular}

The linear regression analysis results show that the "English Conversation" course and the "English Listening Training" course have a significant help on the listening test scores of the TOEIC, and the "Advanced Writing" course has a significant help on the reading test results of the TOEIC because of the corresponding p-values of coefficients are below than 0.05 . With each grade of the TOEIC test, as the grade improves, the listening test and reading test results will interact with the test results of the previous semester.

Compare MLR and SVR, in the root mean square error (RMSE), the value of MLR is bigger than SVR. For example, in the third-grade spring class, the total score of LR is 133.0488, SVR is 38.0821, the value of SVR is much smaller than LR. As shown in Table 1. In the mean absolute error (MAE), MLR is between 21 and 63, and SVR is between 14 and 34 in Table 2. Comparing both, the range of results of SVR prediction is smaller and more accurate than the prediction results of MLR.

\section{Conclusion}

The research results show that the prediction result of SVR analysis is more accurate than the prediction of MLR analysis. Hence, we suggest the department can analyze and predict the TOEIC scores of students at the end of the semester. Moreover, the department can provide additional courses or workshops in the summer or winter vacations for the students whose scores below certain criteria. In addition, teachers can provide some personalized textbooks according to the students' expected achievements to improve the students' academic achievements on TOEIC, as a basis for checking students' learning effectiveness. 


\section{References}

Chen, Jheng-Fong (2011). Evaluating aerosol size distribution by non-linear regression. Retrieved from (in Chinese). Chang Jung Christian University, Tainan, Taiwan. http://dx.doi.org/10.6833/CJCU.2011.00003

Chun Shin Co., Ltd. (2019). 2018 Survey Report on Talent Internationalization and Foreign Language Function Management of Large Taiwanese Enterprises (in Chinese). Retrieved from http://www.toeic.com.tw/news.jsp

Chun Shin Co., Ltd. (2020). TOEIC Taiwan Statistics Report (January to December 2019) (in Chinese), Newsletter, 55, 1-4.

Donald E. Powers, Yu, Feng and Yan, Fred (2013). The TOEIC® Listening, Reading, Speaking, and Writing Tests: Evaluating Their Unique Contribution to Assessing English-Language Proficiency, The Research Foundation for the TOEIC Tests: A Compendium of Studies: Volume II. Princeton, NJ: Educational Testing Service, 2, 3.1-3.13

Educational Testing Service (2019). 2018 Report on Test Takers Worldwide: The TOEIC® Listening and Reading Test. Retrieved from https:/www.ets.org/s/toeic/pdf/2018-report-on-test-takersworldwide.pdf

Kong, Fan-Yu, Xu, Rui-Hua, Yao, Sheng-Yong (2007). Study on Support Vector Regression for Traffic Volume Forecast and Parameters Selection (in Chinese), Computer Engineering, 33(5), 20-28.

Lu, Hui-Fen (2017). A Kernel-based Feature Selection Method for Support Vector Regression (in Chinese) (Unpublished doctoral dissertation). National Taichung University of Education, Taichung, Taiwan.

Lu, Si-Xian (2015). Applying Support Vector Regression to Predict Chiller Performance of Air Conditioning System (in chinese) (Unpublished doctoral dissertation). National Taipei University of Technology, Taipei, Taiwan.

National Development Council (2019). Blueprint for the Development Taiwan into a Bilingual National by 2030 (in Chinese). Retrieved from https://www.ndc.gov.tw

Qiu, Hao-zheng (2013). Quantitative research and statistical analysis: SPSS (PASW) data analysis example, Wunan Book Publishing Co., Ltd.

T.H. Lin, S.S. Lai (2007). Using Nonlinear Regression to Establish Objective Evaluation Model for the Visual Texture of Fabrics (in Chinese). Taiwan Textile Research Journal, 17(2), 43-48. 